\title{
HYDROXYAPATITE AND ZINC OXIDE BASED TWO-LAYER COATING, DEPOSITED ON TI6AL4V SUBSTRATE
}

\section{LEONID SUKHODUB ${ }^{1}$, ANTON PANDA ${ }^{2}$ LUIDMILA SUCHODUB ${ }^{1}$, MARIIA KUMEDA ${ }^{1}$, KONSTANTYN DYADYURA ${ }^{1}$, IVETA PANDOVA2}

${ }^{1}$ Sumy State University, Ministry of Education and Science of Ukraine, Sumy, Ukraine

${ }^{2}$ Thechnical University of Kosice,Department of Manufacturing Technologies, Faculty of Manufacturing Technologies with a seat in Presov, Slovak Republic

DOI : 10.17973/MMSJ.2019_12_2019030

e-mail : anton.panda@tuke.sk

At first two-layer HA-ZnO/Alg coating was obtained on the preanodized Ti6Al4V substrates by the thermal substrate deposition method (TSD). In frame of this work TSD method was at first applied for obtaining $\mathrm{ZnO}$ coating from aqueous alginate-containing solutions on a pre-deposited $\mathrm{OH}$ layer. XRD, SEM analyzes show that the biopolymer has a significant influence on the coatings formation, their morphology, texture, structure of $\mathrm{ZnO}$ nanoparticles. The average rate of $\mathrm{HA}$ deposition and $\mathrm{ZnO}$ deposition from alginate containing solution are $4 \mu \mathrm{m} / \mathrm{min}$ and $30 \mu \mathrm{m} / \mathrm{min}$, respectively. In the presence of alginate boll-shaped $\mathrm{ZnO}$ microparticles are formed on the HA layer, consisting of needle-shaped crystals. Obtained coating is promising for medical implants, based on titanium and its alloys, because they potentially have both bioactivity and antibacterial activity.

KEYWORDS

Thermal substrate deposition, hydroxyapatite, zinc oxide, alginate, coating

\section{INTRODUCTION}

The surface modification of metal implants is one of the promising methods for improving the physico-mechanical and biological properties of these materials. The development of implants with high functionality is an urgent problem to solve. The decisive factor in the osteointegration of bioinert metal implants is the condition of their surface, which borders on the patient's bone tissue. Bioactive coatings with a developed porous surface, functionalized with biomolecules and drugs, should promote active formation of new bone tissue. Biological apatite, that is a part of the bone tissue, includes a number of the inorganic ions such as $\mathrm{Ca}^{2+}, \mathrm{Mg}^{2+}, \mathrm{Sr}^{2+}, \mathrm{Ba}^{2+}, \mathrm{Pb}^{2+}, \mathrm{Zn}^{2+}, \mathrm{Cu}^{2+}$, $\mathrm{Na}^{+}, \mathrm{K}^{+}, \mathrm{Fe}^{3+}$. Established the fact of increasing biological activity of apatite as a result of the inclusion of their composition of small number of zinc, magnesium, silver ions [Mestres 2012]. Among ceramics calcium phosphate orthophosphates, hydroxyapatite $\mathrm{Ca}_{10}\left(\mathrm{PO}_{4}\right)_{6}(\mathrm{OH})_{2}(\mathrm{HA})$, is most promising for coating of metal implants due to chemical similarity to bone mineral [Dorozhkin 2016]. Bioactive coatings based on calcium phosphates and biomolecules are applied to the surface of the metallic implants. It is known that the hybrid organic-inorganic structure initiates pliable bone. Natural polysaccharide alginate (Alg) is widely used for bone tissue engineering [Kuen 2012, Vojtko 2014], also for the stabilization of inorganic nanoparticles [Trandafilovic 2012]. The widespread use of drugs with antimicrobial action has led to the formation of microorganism resistance against antibiotics. To dissolving this problem, the inorganic substances are used for the initiation of a controlled reaction in the tissues and provision of antimicrobial activity. It is known that $\mathrm{ZnO}$-based materials have a pronounced biocompatibility, are characterized by high limit strength, absolute mechanical hardness, as well as the ability to withstand the harsh operating conditions.

All available methods for the fabrication of HA coating can be divided into four groups [Yang 2009, Balara 2018, Gombar 2013, Janekova 2014, Krehel 2013, Krenicky 2012, Lesso 2010, 2014, Monkova 2013, Mrkvica 2012, Prislupcak 2014, 2016, Peterka 2014, Ragan 2012, Rimar 2014, Sebo 2012, Straka 2013, Zaborowski 2007, Zelenak 2012]: a) thermal spraying techniques, b) vapor deposition techniques, c) wet techniques and d) other deposition techniques. However, most of these methods have a weak side associated with coating surfaces of complex geometry. Besides, the modification of the metals and alloys surface before coating is one of the promising methods for improving the physical, mechanical and biological properties of the received materials [Benea 2015, Lee 2014, Suchanek 2015].

In this paper, we use a thermal substrate deposition (TSD) technique, introduced by Kuroda [Kuroda 2012] and developed by our group [Sukhodub 2003, Yanovska 2011, Yanovska 2012]. Thermal substrate method allows to obtain coatings directly from the solution at neutral $\mathrm{pH}$ and low temperature $(40-100$ $\left.{ }^{\circ} \mathrm{C}\right)$. The method was previously used only for the calcium phosphate deposition on titanium substrates. For the first time, the method was used for the deposition of a biologically active $\mathrm{ZnO}$ coating on the surface of a previously deposited calcium phosphate layer.

\section{MATERIALS AND METHODS}

\subsection{Materials}

The following compounds were used for synthesis: zinc nitrate $\mathrm{Zn}\left(\mathrm{NO}_{3}\right)_{2} \times 6 \mathrm{H}_{2} \mathrm{O}$, anhydrous calcium chloride $\mathrm{CaCl}_{2}$, orthophosphoric acid $\mathrm{H}_{3} \mathrm{PO}_{4}$, sodium hydroxide $\mathrm{NaOH}, 25 \%$ hydrous ammonia $\mathrm{NH}_{4} \mathrm{OH}$, sulfuric acid $\mathrm{H}_{2} \mathrm{SO}_{4}$, sodium fluoride $\mathrm{NaF}$, sodium alginate (E401, low viscosity) manufactured by Shanghai Chemical Company Ltd, China. All components were analytically pure and used without further purification.

\subsection{Methods for the obtaining of coatings}

\section{Preparation of the titanium substrate surface}

Ti6Al4V template $(20 \times 1,8 \times 0.9 \mathrm{~mm})$ have been used as an experimental substrate. The sample before deposition was polished with SiC paper and washed with ethanol and deionized water in an ultrasonic cleaner, followed by anodizing for 1 hour at room temperature in an electrolyte of the next composition: $\mathrm{H}_{2} \mathrm{SO}_{4}-20 \% \mathrm{w} / \mathrm{w}$; $\mathrm{NaF}-0.5 \% \mathrm{w} / \mathrm{w}$ to form a $\mathrm{TiO}_{2}$ layer on the surfaces. The direct current density of $1-1.5 \mathrm{~A} / \mathrm{dm}^{2}$ was maintained for the first 5 minutes with the voltage up to $12 \mathrm{~V}$. The subsequent anodizing process was carried out without adjusting the current value, its density was about $0.2 \mathrm{~A} / \mathrm{dm}^{2}$. Lead and titanium plates were used as cathode and anode, respectively. Anodized titanium substrate was annealed at $500^{\circ} \mathrm{C}$ for 1 hour in air in a furnace, followed with ethanol treatment and washing with deionized water.

\section{Deposition of the be-layer HA-ZnO/Alg coating on the Ti6Al4V substrate}

HA coating. Deposition of hydroxyapatite was performed on titanium substrate by the TSD method from $200 \mathrm{ml}$ of the 
solution, containing $0.01 \mathrm{M} \mathrm{CaCl} 2$ and $0.006 \mathrm{M} \mathrm{H}_{3} \mathrm{PO}_{4}$. The solution $\mathrm{pH}$ value was adjusted to 6.52 by $10 \mathrm{M} \mathrm{NaOH}$. The anodized Ti6Al4V substrate was immersed in prepared solution and an alternating electric current $(2 \mathrm{~A})$ was passed through the substrate for 60 minutes, resulting in a substrate heated to $95^{\circ} \mathrm{C}$. To prevent spontaneous calcium phosphate formation in the whole volume when heating and to prevent a depletion of the solution on $\mathrm{Ca}^{2+}$ and $\mathrm{PO}_{4}{ }^{3-}$ ions, a cooling system was used. As a result, the temperature in the whole volume of the mixture was about $25^{\circ} \mathrm{C}$, while the substrate temperature was about $95^{\circ} \mathrm{C}$.

$5 \mathrm{CaCl}_{2}+3 \mathrm{H}_{3} \mathrm{PO}_{4}+10 \mathrm{NaOH} \rightarrow \mathrm{Ca}_{5}\left(\mathrm{PO}_{4}\right)_{3} \mathrm{OH}+10 \mathrm{NaCl}+9 \mathrm{H}_{2} \mathrm{O}$

$\mathrm{HA}-\mathrm{ZnO} /$ Alg coating. The HA coating obtained above was used as the bottom layer in a $\mathrm{HA}-\mathrm{ZnO} / \mathrm{Alg}$ be-layer coating. The substrate coated with HA without detaching from the electrodes was thoroughly washed with deionized water, followed by immersion in the $\mathrm{ZnO}$ nanoparticles containing solution to precipitate $\mathrm{ZnO} / \mathrm{Alg}$.

The upper $\mathrm{ZnO} / \mathrm{Alg}$ coating was obtained by next procedure: alginate from brown algae was used in the present study. $3 \mathrm{~g}$ of sodium alginate was dissolved in $100 \mathrm{~mL}$ of $0.01 \mathrm{M} \mathrm{NaOH}$ and 4 $\mathrm{mL}$ of this $3 \%$ alkaline sodium alginate solution was added drop

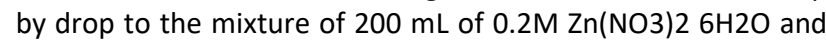
$30 \mathrm{ml}$ of $25 \% \mathrm{w} / \mathrm{w}$ ammonia under vigorous agitation to obtain the transparent alkaline solution, containing $\mathrm{ZnO}$ nanoparticles. The obtained solution placed into the shaker and agitated for $0.5 \mathrm{~h} \mathrm{(rpm} \mathrm{200)}$ at room temperature.

Formation of the $\mathrm{ZnO}$ nanoparticles in the solution occurs according to the following chemical reaction [Zhang 2007]:

$\mathrm{Zn}^{2+}+4 \mathrm{OH}^{-} \rightarrow \mathrm{Zn}(\mathrm{OH})_{4}{ }^{2-}$ and $\mathrm{Zn}(\mathrm{OH})_{4}{ }^{2-} \rightarrow \mathrm{ZnO}+2 \mathrm{H}_{2} \mathrm{O}+2 \mathrm{OH}^{-}$

The pre-coated by $\mathrm{HA}$ substrate was immersed in prepared solution and an alternating electric current (2A) was passed through the substrate for 20 minutes, resulting in a substrate heated to $80^{\circ} \mathrm{C}$. This created favorable reaction conditions for the deposition of $\mathrm{ZnO} / \mathrm{Alg}$ nanoparticles on the titanium substrate surface.

After the deposition, the substrate with be layer coating was gently washed with deionized water and dried at room temperature in an air atmosphere.

\subsection{Investigation methods \\ XRD analysis}

The X-ray diffraction studies of the sample crystallographic structure were performed on the automatized diffractometer DRON 3 (LTD "Burevestnik», www.bourevestnik.ru). CuK $\alpha-$ radiation (wavelength $0.154 \mathrm{~nm}$ ) with $\theta 2 \theta$ Bragg-Brentano geometry ( $2 \theta$ is the Bragg angle) was used. The values of current and voltage on the $X$ ray tube were $20 \mathrm{~mA}$ and $40 \mathrm{kV}$, respectively. The scan of the samples was carried out in the continuous registration mode $(1 / \mathrm{min}$ rate) and $2 \theta$ range from $10^{\circ}$ to $90^{\circ}$. Experimental results were transferred directly to the experimental support package DifWin 1 (LTD «Etalon PTS», www.specord.ru) for the preprocessing. Identification of the crystal phases was performed using the JCPDS (Joint Committee on Powder Diffraction Standards) card catalog. More details in [Kuznetsov 2014].

\section{SEM analysis}

The surface morphology of the samples was examined using a scanning electron microscope (SEM, REMMA-102), produced by SELMI (Ukraine). Images were made in the secondary electron mode with an accelerating voltage $20 \mathrm{kV}$ and a beam current of 1-10 A.

\section{RESULTS AND DISCUSSION}

In this paper, the modified thermal substrate deposition method from aqueous solutions of precursors was used to obtain bioactive $\mathrm{ZnO}$ and $\mathrm{HA}$ coatings on the metal (Ti6Al4V) substrates. The application of this method for both $\mathrm{ZnO}$ and $\mathrm{HA}$ coatings is explained by the similarity of the physico-chemical processes to obtain these types of coatings. It is known that the solubility of $\mathrm{HA}$ in an aqueous solution decreases with increasing temperature and that the relationship between the $\mathrm{HA}$ solubility product, $\mathrm{KSP} /\left(\mathrm{mol} \times \mathrm{dm}^{-3}\right)^{9}$, and the temperature, $T / K$, is given by [Elliot 1994]

$\log \mathrm{KSP}=-8219.41 / \mathrm{T}-1.6657-0.098215 \times \mathrm{T}$

From our testing experiments we believe that the same properties are manifested by $\mathrm{ZnO}$, so the deposition and formation of $\mathrm{ZnO}$ nanostructured coating on the Ti6Al4V substrate occurs approximately at the same temperatures as that for HA $\left(90-100^{\circ} \mathrm{C}\right)$. As already noted, the deposition process involves the passage of alternating current through a metal substrate immersed in an aqueous solution. As a result, the metal substrate is heated to a temperature of about $100^{\circ} \mathrm{C}$ due to resistive heating (Joule heating), although the hydro process passes under atmospheric pressure.

The methods of the bioactive coatings obtaining are schematically presented in Fig.1.

One of the methods for modifying the surface of a titanium implant is the formation of oxide films $\left(\mathrm{TiO}_{2}\right)$ on it by anodizing, which improve implant anticorrosion resistance. Oxide film also is characterized by high adsorption properties. The film structure contributes to the adhesion of HA to the substrate with subsequent transformation of amorphous $\mathrm{HA}$ into the crystalline state [Suchanek 2017]. As mentioned above, HA coating was deposited on anodized titanium substrate.

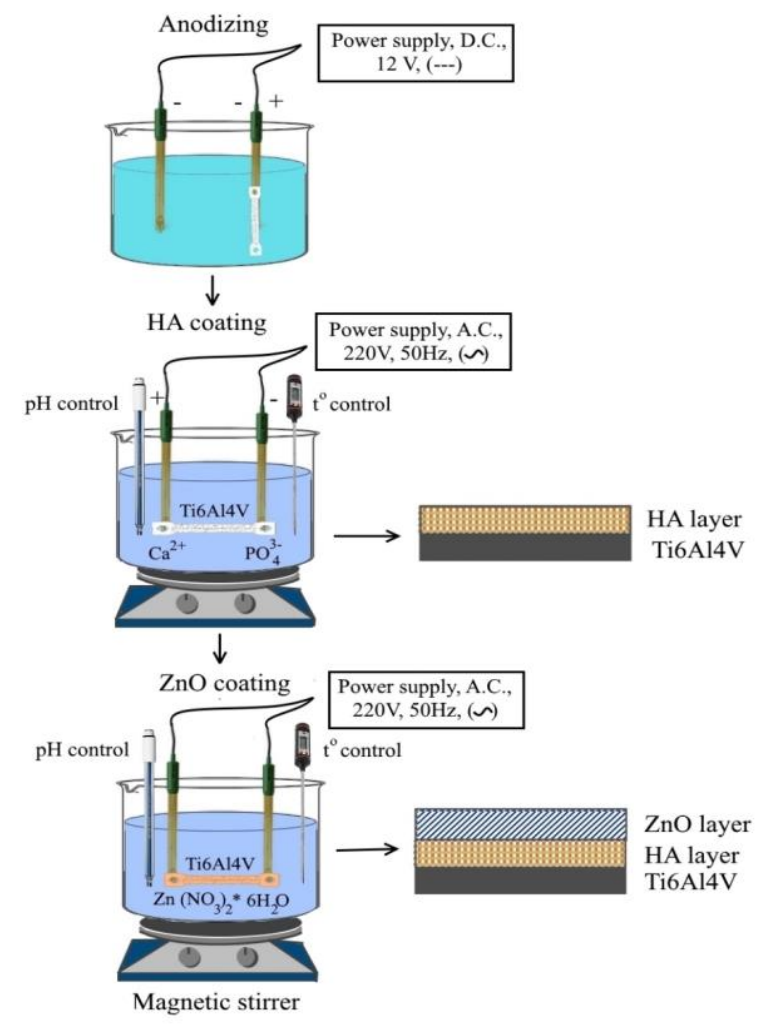

Figure 1. Scheme for the deposition of the two-layer $\mathrm{HA}-\mathrm{ZnO} / \mathrm{Alg}$ coating on an anodized Ti6Al4V substrate using TSD method 


\subsection{SEM analysis.}

Fig. 2 shows the SEM images of the surface morphology of titanium substrates prior and after anodizing process. The surface of the anodized sample differs from the mechanically polished one. The anodizing of titanium led to formation a compact titanium oxide film, which is confirmed by XRD analysis.

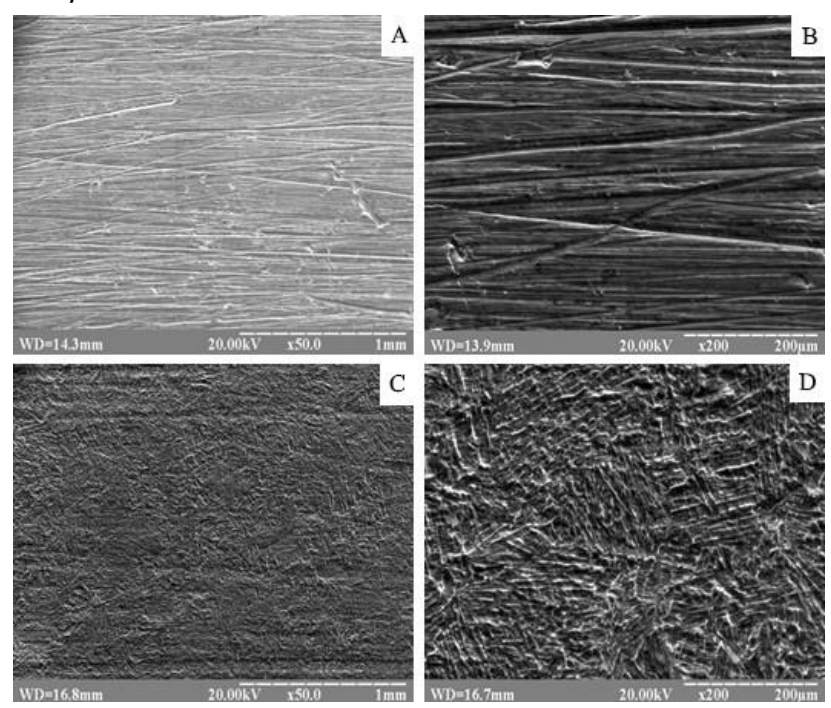

Figure 2. The surface morphology of the Ti6Al4V substrates: (A), (B) before anodizing; (C), (D) - after anodizing

To obtain the be-layer HA-ZnO/Alg bioactive coating, a calcium phosphate (HA) layer was deposited on a titanium substrate using the TSD method. By the XRD results this layer was identified as hydroxyapatite. Fig. 3 ( $A, B)$ shows the morphology of the HA layer surface. Than $\mathrm{ZnO} / \mathrm{Alg}$ layer was deposited on HA surface by the same method. Fig. 3 (C, D) shows the images of the upper layer of $\mathrm{ZnO} / \mathrm{Alg}$ deposited on the $\mathrm{HA}$. $\mathrm{ZnO}$ particles are ball-shaped, with a complex internal structure, represented in the insert (Fig. 3, D).

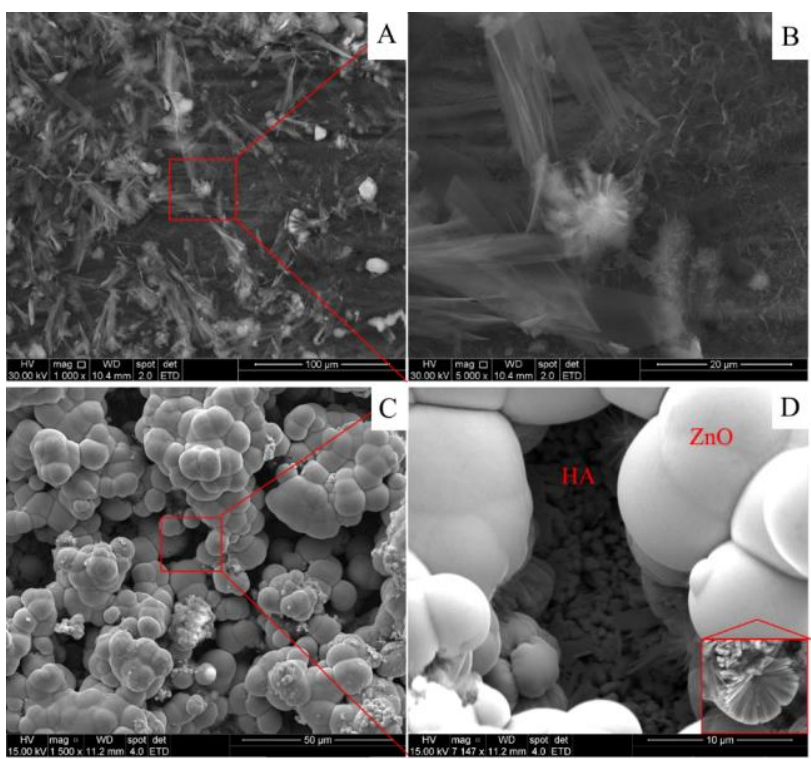

Figure 3. Morphology of the obtained by TSD method coatings: (A), (B) HA coating at different magnifications; (C), (D) - two-layer HA-ZnO/Alg coating: upper $\mathrm{ZnO}$ layer on $\mathrm{HA}$ at different magnification

\subsection{XRD analysis}

The $X$ Ray diffraction patterns of the samples are present on Fig. 4. The major peaks of $\mathrm{ZnO}$, and $\mathrm{HA}$ on the corresponding diffractograms are marked with Miller indexes. The Ti6Al4V anodized substrate diffractogram shows peaks belonging to $\mathrm{TiO}_{2}$ (JCPDS Card No 76-0322 Rutile).

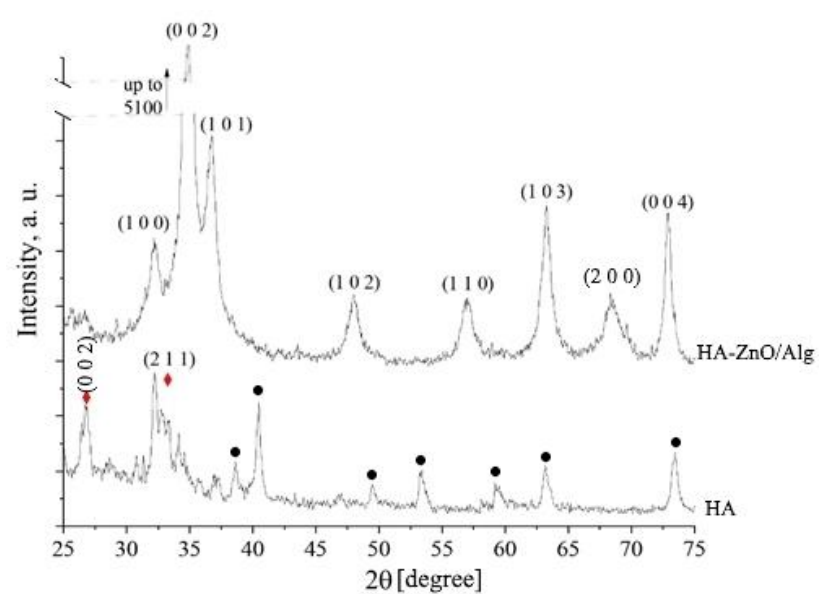

Figure 4. Diffraction patterns from samples. HA coating: (0 02 2) and (2 1 1) lines are the main peaks of $\mathrm{HA}$, marked with $\downarrow$, the TiO2 substrate peaks are marked with $\bullet$; two-layer $\mathrm{HA}$-ZnO/Alg coating with $\mathrm{ZnO} / \mathrm{Alg}$ as upper layer: ZnO peaks are marked with Miller indexes

The phase composition of the HA coated substrate (Fig.4) consists of a HA (JCPDS 9-432). The broad peak for HA indicate that coating is nanocrystalline. The presence of Ti peaks (JCPDS 44-1294) on a diffractogram indicates a low thickness of the HA coating. The thickness of the HA deposited for 60 minutes is $250 \mu \mathrm{m}$. The rate of calcium phosphate deposition of $4 \mu \mathrm{m} / \mathrm{min}$ is significantly lower, than zinc oxide in the case of $\mathrm{ZnO} / \mathrm{Alg}$ coating. $\mathrm{HA}$ is calcium deficient, its atomic ratio $\mathrm{Ca} / \mathrm{P}=1.64$ by RFA analysis.

The diffractogram for upper $\mathrm{ZnO} / \mathrm{Alg}$ layer of $\mathrm{HA}-\mathrm{ZnO} / \mathrm{Alg}$ coating shows intensive peaks of zinc oxide, which overlap the HA ones. Especially intensive peak (002) (up to 5200a.u.) suggests the predominant growth of $\mathrm{ZnO}$ nanoparticles along caxis. The XRD peaks for ZnO/Alg coating, are indexed to hexagonal $\mathrm{ZnO}$ phase and in accordance with the JCPDS Card No $36-1451$.

It is obvious that the texture is present for upper layer ZnO/Alg coating. The Harris method (Harris texture index, $\mathrm{HTI}$ ) was used for its quantitative estimation. The crystallite sizes by Scherrer (L) were evaluated for all major peaks of $\mathrm{ZnO}$ phase, as well as its unit cell parameters ( $a$ and $c, \mathrm{~nm}$ ) using ( $\left.\begin{array}{lll}1 & 0 & 3\end{array}\right)$ and $\left(\begin{array}{lll}0 & 0 & 2\end{array}\right)$ peaks respectively. The good resolution of $\left(\begin{array}{lll}0 & 0 & 2\end{array}\right)$ and $\left(\begin{array}{lll}0 & 0 & 4\end{array}\right)$ peak allowed to separate the contributions from small sizes of coherent scattering regions ( $\left.\mathrm{LwH}_{w}\right)$ and the presence of microstrains $(\varepsilon)$ into the peaks broadening. The separation of these contributions was performed with the Williamson-Hall method [Klug 1974]. These results are present in Table 1.

Table 1. ZnO crystal structure parameters for the two-layer HA$\mathrm{ZnO} / \mathrm{Alg}$ coating on the Ti6Al4V substrate, obtained by TSD method

\begin{tabular}{|c|c|c|c|c|c|c|c|}
\hline Sample & Value & $(100)$ & (002) & (101) & (110) & $\begin{array}{l}\mathrm{L}_{\mathrm{WH}} \cdot \mathrm{nm} \\
\varepsilon \cdot 10^{-3}\end{array}$ & $\begin{array}{l}\text { a. } \mathrm{nm} \\
\text { c. } \mathrm{nm}\end{array}$ \\
\hline \multirow{2}{*}{$\begin{array}{c}\text { HA- } \\
\text { ZnO/Alg }\end{array}$} & L. $n m$ & 13.1 & 38.8 & 8.9 & 9.6 & 110.9 & 0.3217 \\
\hline & HTI & 0.040 & 2.658 & 0.061 & 0.070 & 2.921 & 0.5188 \\
\hline
\end{tabular}

The crystal structure of the be-layer $\mathrm{HA}-\mathrm{ZnO} / \mathrm{Alg}$ coating corresponds to other samples, but shows the highest crystallite sizes and amount of microstrains in $(0 \mathrm{Ol})$ direction. This fact reaffirms the influence of the surface on the structure of $\mathrm{ZnO}$ coating.

In [Kuroda 2012] study, an in vivo investigation of HA/collagen composite coatings on titanium substrates, obtained by TSD 
method, was carried out. It has been found that such composite coatings exhibit high osteoconductivity in the cortical bone. This tendency also occurs for the cancellous bone part. Moreover, HA is known as bioactive, osteoconductive material. Since the HA coating obtained in our work was deposited in similar conditions to the conditions described above, we believe that they can also potentially positively affect the osteoconductivity in the formation of bone tissue.

The study examined the surface of the intraosseous part of screw dental implants in the following areas (SS): the top of the thread, the ramp of the thread, the base of the thread, the distance between the threads of the thread, the groove (Fig. 5). To study the morphology of the coatings, their phase and elemental composition, scanning electron microscopy, X-ray spectral analysis and $\mathrm{X}$-ray structural analysis were used.

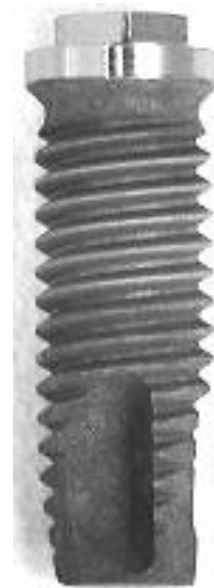

a)

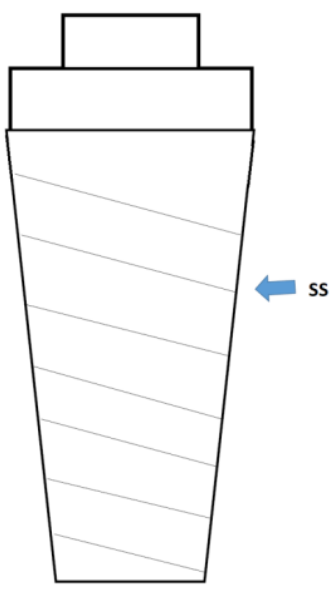

b)
Figure 5. Helical implant with uniform thread and apical groove:

a) Medical implant; b) model for research

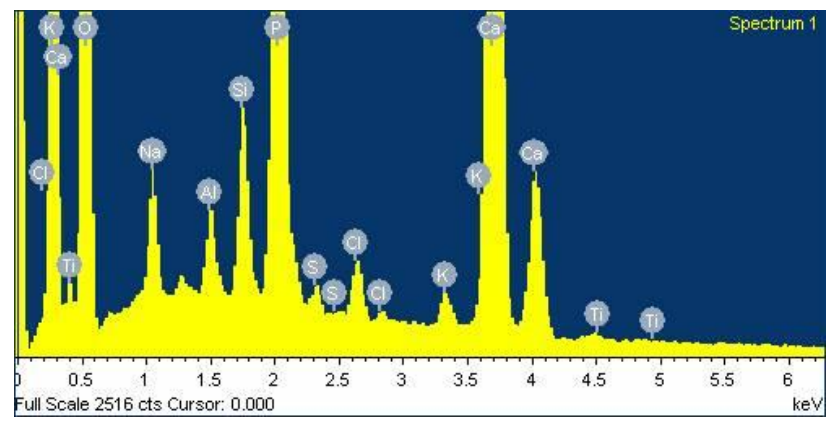

Figure 6. x-ray photograph of samples (located SS)

Table 2. Composition of coating under EDS

\begin{tabular}{|c|c|c|}
\hline Element & Weight\% & Atomic\% \\
\hline C K & 25.89 & 37.73 \\
\hline O K & 42.93 & 46.97 \\
\hline Na K & 0.76 & 0.58 \\
\hline Al K & 0.21 & 0.14 \\
\hline Si K & 0.55 & 0.34 \\
\hline \hline P K & 9.94 & 5.62 \\
\hline Cl K & 0.37 & 0.18 \\
\hline \hline K K & 0.22 & 0.10 \\
\hline \hline Ca K & 19.07 & 8.33 \\
\hline \hline Ti K & 0.07 & 0.03 \\
\hline \hline Totals & 100.00 \\
\hline
\end{tabular}

X-ray structural phase analysis of the samples allowed us to obtain diffraction patterns with characteristic peaks of certain phase components (Fig. 6). In tab. 2 shows the results of decoding $\mathrm{x}$-ray photograph of samples.

Studies performed by scanning electron microscopy showed that a surface with a high level of roughness is formed, containing a large number of microcracks (Fig. 7).
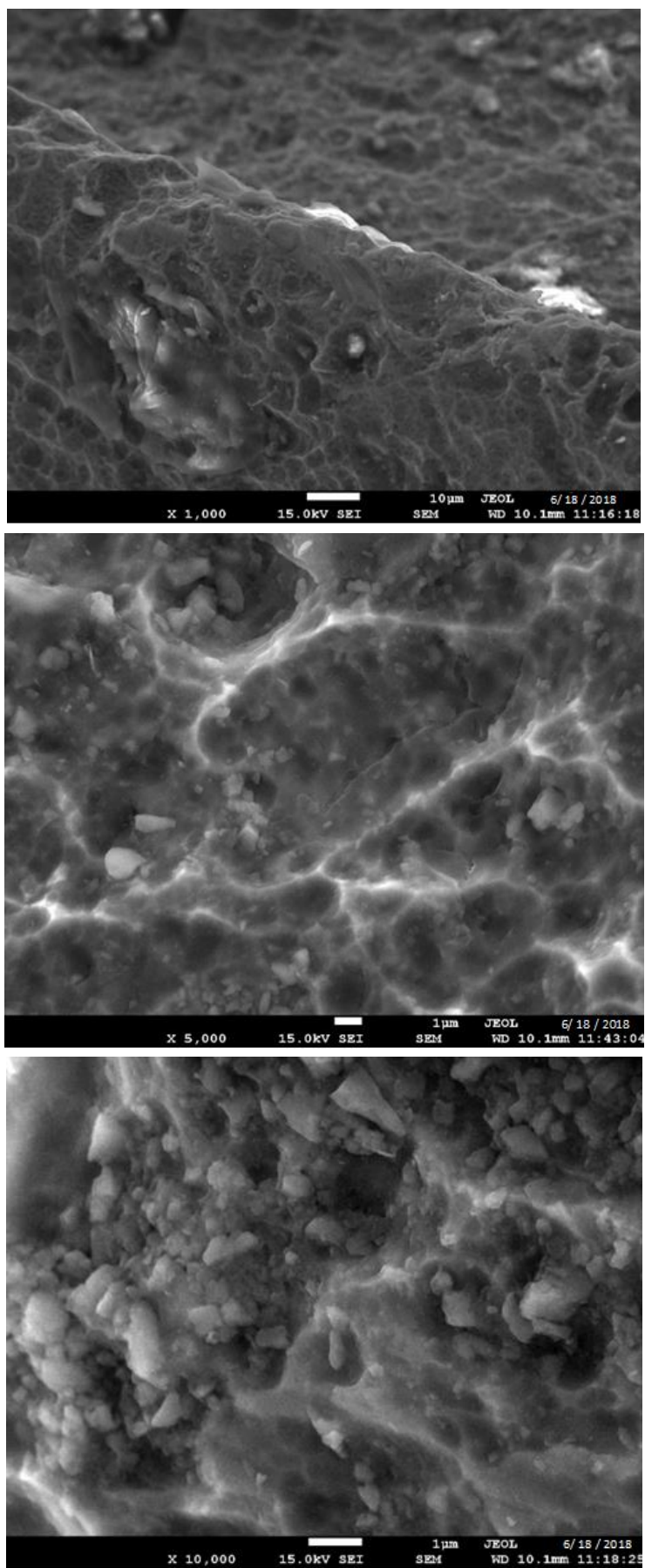

Figure 7. Hydroxyapatite coating is the thinnest polymorphic surface structure formed during the solidification of hydroxyapatite powder particles

The surface of the coating is homogeneous, dense, contains visible defects, cracks and chips. The applied coating repeats the surface relief of the substrate. There is a decrease in the areas of $\mathrm{Ca}_{3}\left(\mathrm{PO}_{4}\right)_{2}$ (the product of decomposition of $\mathrm{HA}$ ). At the same time, calcium pyrophosphate $\mathrm{\gamma}^{-} \mathrm{Ca}_{2} \mathrm{P}_{2} \mathrm{O}_{7}, \mathrm{CaO}$, various calcium bicarbonates and triple calcium hydrogen phosphate $\mathrm{Ca}_{3}\left(\mathrm{PO}_{4}\right)_{2} \mathrm{H}_{2} \mathrm{O}$ are fixed. The crystallinity of the coating is mainly determined by the presence of the hydroxylapatite phase, 
calcium phosphate and ternary calcium phosphate, the latter having the largest crystallite sizes, on the borders of which nanoscale calcium phosphate particles are located (Fig. 7).

\section{CONCLUSIONS}

At first two-layer HA-ZnO/Alg coating was obtained on the preanodized Ti6Al4V substrates by the TSD method. It has been experimentally proved that this method can be effectively applied to obtain not only HA coating, but $\mathrm{ZnO} / \mathrm{Alg}$ coating on a surface of HA inorganic layer. Natural biopolymer alginate has a significant influence on the coatings formation, their morphology, texture, structure of $\mathrm{ZnO}$ nanoparticles. The average rate of the $\mathrm{ZnO}$ deposition from alginate containing solution is $30 \mu \mathrm{m} / \mathrm{min}$, the thickness of the $\mathrm{ZnO} /$ Alg coating, is $600 \mu \mathrm{m}$. The two-layer HA-ZnO/Alg coating is potentially bioactive due to $\mathrm{HA}$ and exhibits antimicrobial activity through the zinc oxide nanoparticles. For this coating an increase in the $\mathrm{ZnO}$ crystallites size and microstrains along the $(0 \mathrm{Ol})$ direction are characteristic. The obtained coatings are promising for medical implants, based on titanium and its alloys, because they potentially have both bioactivity and antibacterial activity.

\section{ACKNOWLEDGEMENTS}

The authors would like to thank the KEGA grant agency for supporting research work and co-financing the project KEGA: 004TUKE-4/2017.

\section{REFERENCES}

[Balara 2018] Balara, M., Duplakova, D., Matiskova, D. Application of a signal averaging device in robotics. Measurement, 2018, Vol. 115, No. 2, pp. 125-132, Issue 5-8, ISSN 0263-2241.

[Benea 2015] Benea, L., Danaila, E., Ponthiaux, P. Effect of titania anodic formation and hydroxyapatite electrodeposition on electrochemical behaviour of Ti-6Al-4V alloy under fretting conditions for biomedical applications. Corrosion Science, 2015, Vol. 91, pp. 262-271.

[Dorozhkin 2016] Dorozhkin, S.V. Calcium orthophosphates (CaPO4): occurrence and properties. Prog. Biomater, 2016, Vol. 5, pp. 9-70.

[Elliot 1994] Elliot, J.C. Structure and Chemistry of Apatite and Other Calcium Orthophosphates. Studies in Inorganic Chemistry 18, Elsevier, Amsterdam, 1994; Vol. 230.

[Gombar 2013] Vagaska, A., Kmec, J. and Michal, P. Microhardness of the Coatings Created by Anodic Oxidation of Aluminium. Applied Mechanics and Materials, 2013, Vol. 308, pp. 95-100.

[Janekova 2014] Janekova, J., Kovac, J. and Onofrejova, D. Modelling of Production Lines for Mass Production of Sanitary Products. Procedia Engineering, 2014, Vol. 96, pp. 330-337.

[Klug 1974] Klug, H.P. and Alexander, L.E. X-ray diff stalline and amorphous materials, 2nd ed.; Wiley: Weinheim, 1974.

[Krehel 2013] Krehel, R., Straka, L. and Krenicky, T. Diagnostics of Production Systems Operation Based on Thermal Processes Evaluation. Applied Mechanics and Materials, 2013, Vol. 308, pp.121-126.

[Krenicky 2012] Krenicky, T. and Rimar, M. Monitoring of vibrations in the technology of AWJ. Key Engineering Materials, 2012, Vol. 496, pp. 229-234.

[Kuen 2012] Kuen, Y.L. and David, J. Alginate: Properties and biomedical applications. Progress in Polymer Science, 2012, Vol. 37, pp. 106-126.
[Kuroda 2012] Kuroda, K. Hydroxyapatite coating of titanium implants using hydroprocessing and evaluation of their osteoconductivity. Bioinorganic Chemistry and Applications, 2012, p. 730693.

[Kuznetsov 2014] Kuznetsov, V.M., Sukhodub, L.B., Sukhodub, L.F. Structural and Substructural Features of ApatiteBiopolymer Composites: the Comparison of Data Obtained Using X-Ray Diffraction and Scanning Electron Microscopy with Electron Diffraction. Journal of nano- and electronic physics, 2014, Vol. 6, No. 4, pp. 04039-04043.

[Lee 2014] Lee, K., Mazare, A. and Schmuki, P. One-Dimensional Titanium Dioxide Nanomaterials: Nanotubes. Chemical Reviews, 2014, Vol. 114, No. 19, pp. 9385-9454.

[Lesso 2014] I. Lesso, P. Flegner, J. Futo and Z. Sabova, Utilization of signal spaces for improvement of efficiency of metallurgical process. Metalurgija, 2014, Vol. 53, No. 1, pp. 7577, ISSN 0543-5846.

[Leššo 2010] Leššo, I., Flegner, P., Šujanský, M., Špak, E. Research of the possibility of application of vector quantisation method for effective process control of rock desintegration by rotary drilling. Metalurgija, 2010, Vol. 49, No. 1, pp. 61-65, ISSN 0543-5846

[Mestres 2012] Mestres, G., Le Van, C., Ginebra, M.P. SiliconStabilized $\alpha$-tricalcium phosphate and its use in a calcium phosphate cement: Characterization and cell response. Acta Biomaterialia, 2012, Vol. 8, pp. 1169-1179.

[Monkova 2013] Monkova, K., Monka, P. and Jakubeczyova, D. The research of the high speed steels produced by powder and casting metallurgy from the view of tool cutting life. Applied Mechanics and Materials, 2013, Vol. 302, pp. 269-274.

[Mrkvica 2012] Mrkvica, I., Janos, M. and Sysel, P. Contribution to milling of materials on $\mathrm{Ni}$ base. Applied Mechanics and Materials, 2012, Vol. 217-219, pp. 2056-2059.

[Peterka 2014] Peterka, J. and Pokorny, P. Influence of the Lead Angle from the Vertical Axis Milling on Effective Radius of the Cutter. Key Engineering Materials, 2014, Vol. 581, pp. 44-49, ISSN 1013-9826.

[Prislupcak 2016] Panda, A. Comparison and analysis of the flow rate. Key Engineering Materials, 2016, Vol. 663-696, pp. 197-204, ISSN 1013-9826.

[Prislupcak 2014] Prislupcak, M., et al. Diagnostic and experimental valuation on progressive machining unit. Applied Mechanics and Materials, 2014, Vol. 616, pp. 191-199, ISSN 1660-9336.

[Ragan 2012] Ragan, E., Dobransky, J., Baron, P., Kocisko, M., Svetlík, J. Dynamic of taking out molding parts at injection molding. Metallurgy, 2012, Vol. 51, No.4, pp. 567-570.

[Rimar 2014] Rimar, M., Fedak, M., Mihalcova, J. and Kuna, S. Adaptive rejection filter for the drives stabilization of pressure die-casting machines. Advances in Mechanical Engineering. 2014, pp. 1-10, ISSN 1687-8132.

[Sebo 2012] Sebo, J., Svetlik, J., Fedorcakova, M. and Dobransky, J. The comparison of performance and average costs of robotic and human based work station for dismantling processes. Acta Technica Corviniensis: Bulletin of engineering, 2012, Vol. 5, No. 4, pp. 67-70, ISSN 2067-3809.

[Straka 2013] Straka, L., Corný, I. and Krehel, R. Evaluation of Capability of Measuring Device on the Basis of Diagnostics. Applied Mechanics and Materials, 2013, Vol. 308, pp. 69-74.

[Suchanek 2015] Suchanek, K. et al. Crystalline hydroxyapatite coatings synthesized under hydrothermal conditions on 
modified titanium substrates. Materials Science and Engineering C, 2015, Vol. 51, pp. 57-63.

[Suchanek 2017] Suchanek, K. et al. The influence of nanoporous anodic titanium oxide substrates on the growth of crystalline hydroxyapatite coatings. Mat. Chem. and Phys., 2017, Vol. 186, pp. 167-178.

[Sukhodub 2003] Sukhodub, L.B. et al. Improved thermal substrate method with cooling system for hydroxyapatite coatings on titanium substrates. Annual Report, Institut für Kernphysik, Westfalishe Wilhelmsuniversität Münster, 2002/2003, pp. 86-88.

[Trandafilovic 2012] Trandafilovic, L.V. et al. Fabrication and antibacterial properties of $\mathrm{ZnO}$-alginate nanocomposites. Carbohydrate Polymers, 2012, Vol. 88, pp. 263-269.

[Vojtko 2014] Vojtko, I., Simkulet, V., Baron, P. and Orlovsky, I. Microstructural Characteristics Investigation of the ChipMaking Process after Machining. Applied Mechanics and Materials, 2014, Vol. 616, pp. 344-350, ISSN 1660-9336.

[Yang 2009] Yang, H. et al. Comparative study of cytotoxicity, oxidative stress and genotoxicity induced by four typical nanomaterials: the role of particle size, shape and composition. J. Appl. Toxicol., 2009, Vol. 29, No. 1, pp. 69-78.

\section{CONTACTS:}

Prof. M. S. E. (Ing.) Anton Panda, PhD.

Technical University Kosice with seat in Presov

FVT, Department of Manufacturing Technologies

Bayerova 1, Presov, 080 01, Slovak Republic

e-mail: anton.panda@tuke.sk
[Yanovska 2011] Yanovska, A. et al. Synthesis and characterization of hydroxyapatite-based coatings for medical implants obtained on chemically modified Ti6AI4V substrates. J. Surf. Coat. Technol., 2011, Vol. 205, pp. 5324-5329.

[Yanovska 2012] Yanovska, A. et al. A study of brushite crystallization from calcium-phosphate solution in the presence of magnesium under the action of a low magnetic field. Materials science and engineering C, 2012, Vol. 32, pp. 18831887.

[Zaborowski 2007] Zaborowski, T. Ekowytwarzanie. Gorzow, 2007, $100 \mathrm{p}$.

[Zelenak 2012] Zelenak, M. et al. Comparison of mechanical properties of surface layers with use of nanoindentation and microindentation tests. Metalurgija, 2012, Vol. 51, No. 3, pp. 309-312.

[Zhang 2007] Zhang, Y. and Mu, J. Controllable synthesis of flower- and rod-like $\mathrm{ZnO}$ nanostructures by simply tuning the ratio of sodium hydroxide to zinc acetate. Nanotechnology, 2007, Vol. 18, p. 075606 